\title{
ESTUDO DE IMPACTO DE VIZINHANÇA: AVALIAÇÃO APÓS 15 ANOS DE ESTATUTO DA CIDADE ${ }^{1}$
}

Fabiana Wütrich²

DOI: 10.5752/P.2316-1752.2017v24n34p140

\section{Resumo}

O artigo objetiva contribuir com a discussão da aplicabilidade do Estudo de Impacto de Vizinhança, instrumento de política urbana incluído no Estatuto da Cidade. Para tanto, são apresentados dados que permitem o reconhecimento quantitativo da sua incorporação pelos municípios, demonstrando a sua situação 15 anos após aprovação da lei federal, assim como uma análise qualitativa, concentrada no aglomerado metropolitano de Curitiba. Os resultados obtidos permitem apontar desafios e recomendações de modo a orientar a elaboração de leis específicas no âmbito municipal.

Palavras-chave: Estudo de Impacto de Vizinhança. Estatuto da Cidade. Aglomerado Metropolitano de Curitiba.

\footnotetext{
1. Este artigo toma por base as investigações decorrentes do mestrado de Fabiana Wütrich, no Programa de Pós-Graduação em Geografia (PPGGEO) da Universidade Federal do Paraná (UFPR), sob orientação da Prof. ${ }^{a}$ Dr. ${ }^{a}$ Gislene Pereira. 2. Arquiteta Urbanista, mestre em Geografia pela Universidade Federal do Paraná (UFPR), Curitiba, Paraná, Brasil. E-mail: fabiana.wutrich@gmail.com
} 


\section{NEIGHBORHOOD IMPACT STUDY: EVALUA- CION 15 YEARS AFTER THE CITY STATUTE}

\begin{abstract}
The article aims to contribute to the discussion of the applicability of the Neighborhood Impact Study, an urban policy instrument included in the City Statute. This paper shows the incorporation of this instrument by the municipalities 15 years after the approval of the federal law, as well as qualitative analysis, focused at the Metropolitan Agglomerate of Curitiba. Results allow us to point out challenges and recommendations to guide the elaboration of specific laws in the scope of other municipalities.
\end{abstract}

Keywords: Neighborhood Impact Study. City Statute. Metropolitan Agglomerate of Curitiba.
ESTUDIO DE IMPACTO URBANO: EVALUACIÓN 15 AÑOS DESPUÉS DEL ESTATUTO DE LA CIU$D A D$

\section{Resumen}

Este articulo pretende contribuir a la discusión acerca de la aplicabilidad del Estudio de Impacto Urbano, instrumento de gestión y política urbana oriundo del Estatuto de la Ciudad. Los datos presentados permiten el reconocimiento cuantitativo de su incorporación por los municipios 15 años después de la adopción de la ley federal. Permiten también un análisis cualitativo centrado en la Aglomeración Metropolitana de Curitiba. Los resultados señalan cuestiones principales y recomendaciones para guiar la gestión y desarrollo de leyes municipales específicas.

Palabras-claves: Estudio de Impacto Urbano. Estatuto de la Ciudad. Aglomeración Metropolitana de Curitiba 


\section{Introdução}

Durante o constante e contínuo processo de produção do espaço urbano, os interesses dos diversos agentes sociais podem colidir (GOTTDIENER, 1997), tornando necessárias intervenções que permitam minimizar tais conflitos. Os instrumentos de planejamento urbano tradicionalmente utilizados, como o plano diretor e a lei de zoneamento, uso e ocupação do solo, por exemplo, nem sempre são capazes de identificar ou evitar tais conflitos, ou mesmo prever os possíveis impactos que determinados empreendimentos e/ou atividades podem gerar na vizinhança ou na cidade como um todo. Ademais, esses instrumentos tampouco são capazes de informar com precisão a reação e a capacidade de absorção desses impactos, sejam no sistema viário, nas redes de infraestruturas ou até mesmo na oferta de vagas em equipamentos comunitários. Em relação às limitações da lei de zoneamento, por exemplo, ela

por si só não é capaz de mediar todos os conflitos de vizinhança, apesar de, em inúmeras cidades, ter logrado garantir a proteção da qualidade de vida de alguns bairros - principalmente aqueles ocupados por residências unifamiliares em lotes grandes. Estes últimos podem comportar grandes empreendimentos que, mesmo atendendo aos requisitos da Lei, provocam profundos impactos nas vizinhanças: sobrecarga no sistema viário, saturação da infraestrutura - drenagem, esgoto, energia elétrica, telefonia -, sombreamento e poluição so- 
nora, entre outros (CÂMARA DOS DEPUTADOS, 2001, p.198).

Assim, mesmo que tais empreendimentos estejam em conformidade com a legislação, eles podem desencadear impactos em uma vizinhança consolidada ${ }^{3}$ ou que já começa a apresentar sinais de saturação.

Com o propósito de exigir a análise detalhada de determinados tipos de empreendimentos e/ou atividades urbanas, condicionando sua aprovação a um conjunto de medidas adaptativas, mitigadoras e/ou compensatórias, ou mesmo restringindo a implantação dos mesmos, o Estatuto da Cidade (BRASIL, 2001) incluiu no rol de instrumentos de política urbana o Estudo de Impacto de Vizinhança (EIV).

Este artigo objetiva contribuir com a discussão sobre a aplicabilidade do Estudo de Impacto de Vizinhança 15 anos após a aprovação do Estatuto da Cidade. Para tanto, são apresentados dados que permitem o reconhecimento quantitativo da sua incorporação pelos municípios brasileiros, assim como uma análise qualitativa, concentrada no aglomerado metropolitano de Curitiba. Os resultados obtidos permitem apontar desafios e recomendações de modo a orientar a elaboração de leis municipais específicas.

3. No contexto desta pesquisa, entende-se por vizinhança consolidada aquela que possui todos os lotes edificados e cujos parâmetros de ocupação correspondam ao índice máximo permitido pelo zoneamento. 


\section{Estudo de impacto de vizinhança: Conceito, ob- jetivos e características}

O cumprimento da função social da propriedade urbana e da cidade, princípio norteador da política urbana no Brasil pós-Estatuto, também é almejado pelo EIV, uma vez que por meio da sua aplicação se busca separar o direito de propriedade do direito de construir. Isso significa afirmar que, ainda que um proprietário deseje construir em consonância com a legislação urbana, "cada interferência na utilização ou ocupação de um determinado lote urbano produz impactos sobre seu entorno, podendo interferir diretamente na vida e na dinâmica urbana de outros" (CÂMARA DOS DEPUTADOS, 2001, p.198).

Assim, o EIV foi incluído no Estatuto da Cidade (BRASIL, 2001), como um dos instrumentos de política urbana ${ }^{4}$, com a finalidade de mediar possíveis conflitos entre os interesses privados dos agentes produtores do espaço urbano (CAPEL, 1974) e o direito à qualidade de vida daqueles que habitam ou transitam no entorno da área onde se pretende implantar o empreendimento. O EIV avança sobre as limitações dos instrumentos básicos de planejamento urbano, como o plano diretor e a lei de zoneamento (CÂMARA DOS DEPUTADOS, 2001), uma vez que condiciona a aprovação

4. Capítulo II - Dos Instrumentos da Política Urbana; Seção I - Dos Instrumentos em Geral; Art. $4^{\circ}$, inciso $\mathrm{VI}$ - estudo prévio de impacto ambiental (EIA) e estudo prévio de impacto de vizinhança (EIV). 
de determinadas tipologias de empreendimento e/ou atividades com potencial de gerar impactos urbanos a uma análise prévia, (art. 36, Lei n ${ }^{\circ}$ 10.257/01) baseada, minimamente, no conjunto de critérios estabelecidos na mesma Lei Federal (art. 37, Lei n 10.257/01). Esses critérios podem ser complementados no momento de elaboração de lei municipal que deve regulamentar sua aplicação pelos municípios brasileiros. A análise exigida pelo EIV visa potencializar os possíveis impactos positivos e identificar e propor soluções para adaptar, mitigar ou compensar os possíveis impactos negativos que esses empreendimentos podem gerar na vizinhança ou mesmo na cidade como um todo.

Portanto, seu objetivo final é a promoção da democratização da gestão urbana (CÂMARA DOS DEPUTADOS, 2001), já que inclui a participação da população no processo de aprovação de grandes empreendimentos. Dessa forma, ao tornar mais democrático e inclusivo o processo, esse instrumento "consagra o 'Direito de Vizinhança' como parte integrante da política urbana, condicionando o direito de propriedade" (CÂMARA DOS DEPUTADOS, 2001, p.199).

Concorda-se com Rocco (2009), portanto, que reconhece como novidade intrínseca ao EIV o seu papel de "mediador" de interesses entre os agentes produtores do espaço urbano, como proprietários dos meios de produção, proprietários fundiários, promotores imobiliários, o Estado (CAPEL, 1974) e a população, visando garantir a (re)produção 
de cidades sustentáveis.

O Estatuto da Cidade (Lei Federal $n^{\circ}$ 10.257/01) dedica três artigos (36 ao 38) para definir as diretrizes para implementação do EIV. O artigo 36 determina que cabe ao município, por meio de lei municipal posterior, estabelecer as tipologias de empreendimentos e/ou atividades, privadas ou públicas, que merecerão sua aplicação. Conforme afirma

\begin{tabular}{|c|c|c|}
\hline \multirow{2}{*}{$\begin{array}{l}\text { CRITERIOS } \\
\text { PREVISTOS NO } \\
\text { ART. } 37\end{array}$} & \multicolumn{2}{|c|}{ OBSERVAÇOES SOBRE OS CRITERIOS DO ART. 37} \\
\hline & AUTOR(ES) & COMENTARIOS \\
\hline $\begin{array}{l}\text { Adensamento } \\
\text { populacional }\end{array}$ & $\begin{array}{l}\text { Vencesslau } \\
\text { (2009); Plotto, } \\
\text { Santoro e } \\
\text { Freitas (2013) }\end{array}$ & $\begin{array}{l}\text { Analisar descie a capacidade da infraesțutura e da rede } \\
\text { de serviços públicos da área de influência até aspectos } \\
\text { relacionados a impactos socioeconâmicos, como a } \\
\text { migração de mảo de abra au mesmo gentrificaçăo, por } \\
\text { exemplo. }\end{array}$ \\
\hline $\begin{array}{l}\text { Equiparnentos } \\
\text { urbanos e } \\
\text { comunitários }\end{array}$ & $\begin{array}{l}\text { Menegassi e } \\
\text { Osćrio (2002); } \\
\text { Venceslau } \\
(2009)\end{array}$ & 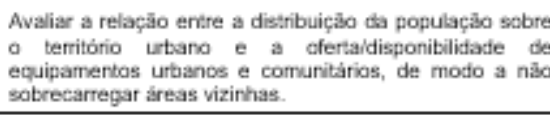 \\
\hline $\begin{array}{l}\text { Uso e ocupaçã̃o do } \\
\text { solo }\end{array}$ & $\begin{array}{l}\text { Vencesiau } \\
(2008)\end{array}$ & $\begin{array}{l}\text { Analisar a adequaçẩo do empreendimento ao uso do soik } \\
\text { predefirido, avaliando-se as usos e ocupaçōes existentes } \\
\text { e possiveis para os lotes viźnhos, assim como possíveis } \\
\text { tendéncias de coupaçẩo pós-empreendimento. }\end{array}$ \\
\hline $\begin{array}{l}\text { Valorizaçāo } \\
\text { imobiliária }\end{array}$ & $\begin{array}{l}\text { Menegassi e } \\
\text { Oscrio (2002); } \\
\text { Cavalcanti e } \\
\text { Lins (2006); } \\
\text { Vencesiau } \\
\text { (2008) } \\
\end{array}$ & 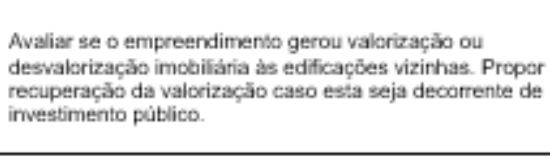 \\
\hline $\begin{array}{l}\text { Geraçăo de tráfego } \\
\text { e demanda por } \\
\text { transporte coletivo } \\
\end{array}$ & $\begin{array}{l}\text { Vencesiau } \\
(2008)\end{array}$ & $\begin{array}{l}\text { Avaliar se tanto o sistema como a infraestrutura viáris } \\
\text { existente comportam a nova carga de veículos e viagens } \\
\text { a serem geradas pelo empreendimento. }\end{array}$ \\
\hline $\begin{array}{l}\text { Ventilação e } \\
\text { iluminaçå̉o }\end{array}$ & $\begin{array}{l}\text { Menegassi e } \\
\text { Osćrio (2002) }\end{array}$ & 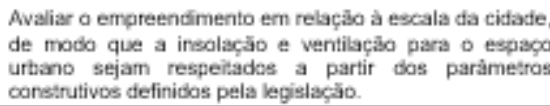 \\
\hline $\begin{array}{l}\text { Paisagem urbana e } \\
\text { patrimênio natural } \\
\text { e cultural }\end{array}$ & $\begin{array}{l}\text { Venceslau } \\
(2008)\end{array}$ & $\begin{array}{l}\text { Verificar a sua compatibilidade do novo empreendimento } \\
\text { com a paisagem urbana. }\end{array}$ \\
\hline
\end{tabular}

Quadro 1 - CRITÉRIOS DO ARTIGO 37 DO ESTATUTO DA CIDADE E OBSERVAÇÕES SOBRE SEUS OBJETIVOS SEGUNDO AUTORES. Fonte: Elaborado pela autora (2016) com base na bibliografia. 
Rocco (2009), por meio dessa determinação federal, a singularidade e autonomia legal de cada municipalidade passam a ser reconhecidas e respeitadas. Entretanto, ao mesmo tempo, surge o risco de parcialidade na definição das tipologias de empreendimentos sujeitos ao EIV, com vistas a favorecer determinado grupo de agentes.

O artigo 37 apresenta um conjunto mínimo de critérios que devem ser analisados previamente à implantação dos empreendimentos, de modo a contemplar o reconhecimento dos efeitos positivos e negativos sobre a qualidade de vida da população residente na área e/ou em suas proximidades. Diversos autores já se debruçaram sobre esses critérios e o quadro a seguir busca apresentar uma sistematização desses entendimentos.

Por fim, o artigo 38 traz à tona a questão da relação entre o EIV e o Estudo de Impacto Ambiental (EIA). Porém, com base na literatura ${ }^{5}$, pode-se encontrar diferentes interpretações para esse artigo, entendendo os instrumentos como: (i) distintos; (ii) complementares ou (iii) similares; o que pode resultar em conflitos no estabelecimento de competências de atuação de cada um deles. 


\section{A evolução da incorporaçãodo EIV pelos mu- nicípios brasileiros 15 anos após a regulamen- tação do Estatuto da Cidade}

Para um reconhecimento quantitativo da evolução da incorporação do EIV pelos municípios brasileiros, foram analisados dados da Pesquisa de Informações Básicas Municipais (MUNIC), do Instituto Brasileiro de Geografia e Estatística (IBGE), que monitora diversas áreas de desenvolvimentos dos municípios, o que inclui aspectos referentes à estrutura, dinâmica e funcionamento das instituições públicas municipais, particularmente as prefeituras, de forma periódica desde 1999. O monitoramento quanto à incorporação dos instrumentos de política urbana pelos municípios brasileiros começou a ser registrado na edição do MUNIC de $2005^{6}$.

No primeiro ano de monitoramento, apenas 7,5\% dos municípios afirmavam possuir o instrumento, o que corresponde, em números absolutos, a 417 municípios. Já em 2008, três anos após o primeiro levantamento de dados, podese observar um salto quantitativo, quando foram contabilizados $12,9 \%$ de municípios com o instrumento presente em seus PDs. No MUNIC 2009 registrou-se novo avanço: 18,9\% ou 1056 municípios afirmavam possuir EIV. Ocorre,

6. Para os pesquisadores responsáveis pelo levantamento, EIV é definido como "o estudo realizado antes da aprovação do empreendimento ou da atividade para mostrar seus efeitos quanto à qualidade de vida da população residente na área e suas proximidades" (MUNIC-IBGE, 2005, p.233). 
porém, uma retração nesse percentual entre os anos de 2009 e 2012, reduzindo-o para 11,6\%.

O grande avanço registrado no ano seguinte, 2013, deve ser analisado com cautela, uma vez que os pesquisadores alertam para uma mudança metodológica no processo de coleta e formatação dos dados relativos aos instrumentos de política urbana a partir de 2013, passando a inserir, em colunas diferentes, os municípios que possuem (i) o instrumento como parte integrante do Plano Diretor; e (ii) o instrumento regulamentado por lei específica. Mais importante, eles reforçam que o quantitativo elaborado nesse momento não possui "comparabilidade perfeita com os resultados de anos anteriores" (MUNIC, 2013, p.55). De fato, muitos municípios que declararam possuir o instrumento anteriormente estavam passando pelo processo de revisão de seus Planos, o que implica no processo de revisão de suas leis e instrumentos de planejamento, ou mesmo sua revogação (MUNIC, 2013). De qualquer maneira, em 2013, o total de municípios que afirmam possuir o instrumento, seja incorporado ao PD ou por meio de lei específica, é de $26,8 \%$ ou 1493 municípios. A atualização dos dados realizada em 2015 apresentou um pequeno aumento desse percentual, indicando que são 1905 municípios que incorporaram o instrumento, o que corresponde a pouco mais de 1/3 do total de municípios brasileiros (GRÁFICO 1).

Outra informação trazida pela pesquisa é a relação inversa 


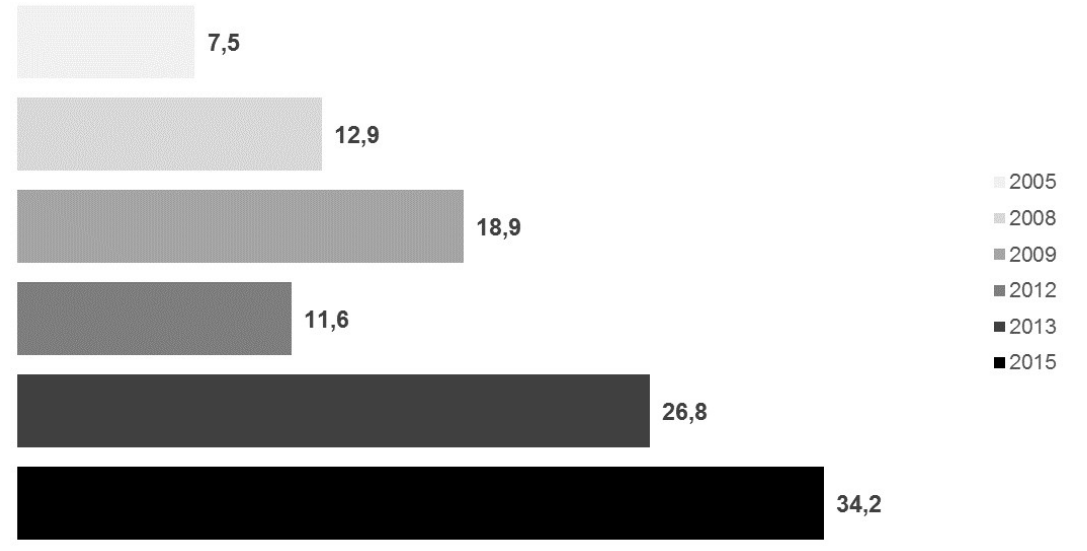

Gráfico 1 - PERCENTUAL DE MUNICÍPIOS BRASILEIROS QUE POSSUEM EIV, 2005 - 2015. FONTE: IBGE, Diretoria de Pesquisas, Coordenação de População e Indicadores Sociais, MUNIC 2005, 2008, 2009, 2012, 2013 e 2015, organizado pela autora (2016).

entre incorporação do EIV no plano diretor e população. Do total de 5570 municípios do país, 19,51\% incorporaram o instrumento, ou 1087 em números absolutos. Sendo que desses, 797 estão no grupo de municípios com até 50.000 habitantes e 290 no grupo de municípios com maior população. A relação entre lei específica e população, por sua vez, é mais equilibrada na Classe 7, que corresponde ao conjunto de municípios com mais de 500 mil habitantes, como mostra o gráfico a seguir.

\section{Estudo de caso: a aplicabilidade do EIV no aglomerado metropolitano de Curitiba7}

O Estatuto da Cidade (BRASIL, 2001) estabelece como obrigatória a elaboração do plano diretor para, dentre outros, 


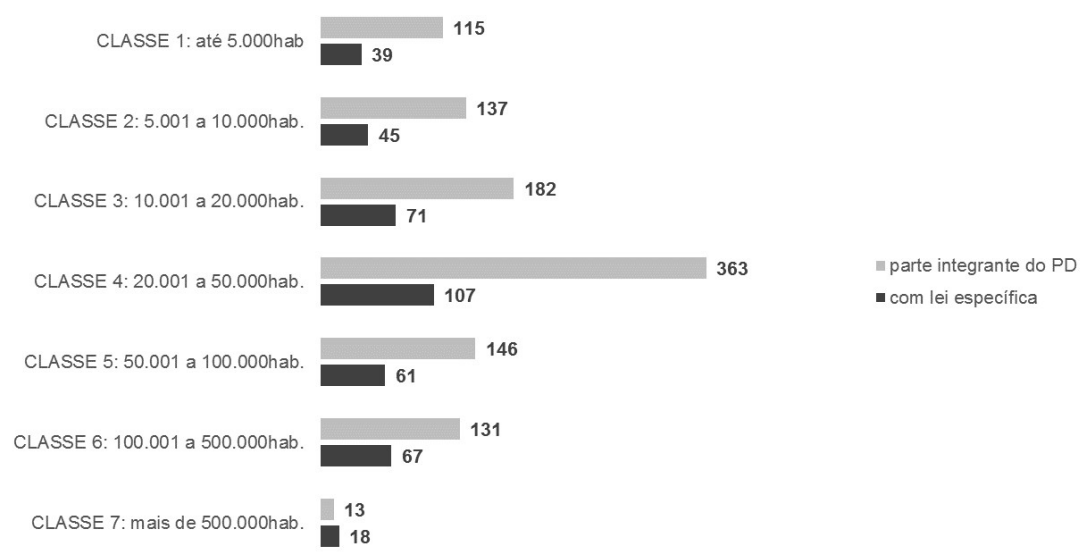

Gráfico 2 - NÚMEROS ABSOLUTOS / PERCENTUAL DA INCORPORAÇÃO DO EIV PELOS MUNICÍPIOS BRASILEIROS, SEGUNDO CLASSE DE POPULAÇÃO, 2013. FONTE: IBGE, Diretoria de Pesquisas, Coordenação de População e Indicadores Sociais, MUNIC 2013, organizado pela autora (2016).

"os municípios pertencentes a regiões metropolitanas e aglomerações urbanas" (art.41, II, Lei Federal n 10.257/01). Também estabelece como obrigatória a sua revisão periódica, a cada 10 anos (art. 40, $3^{\circ}$ ). Assim, torna-se relevante para o encaminhamento da pesquisa empírica reconhecer a situação dos municípios integrantes do aglomerado met-

7. O recorte espacial escolhido para a presente pesquisa foi definido por Firkowski (2001) com base no trabalho Caracterização e Tendências da Rede Urbana Brasileira (IPARDES, 2000), que entende aglomerado metropolitano de Curitiba ou aglomeração de caráter metropolitano como "uma mancha de ocupação derivada de conurbação e/ou periferização, diretamente polarizada pela metrópole, envolvendo municípios limítrofes com contiguidade, continuidade e/ ou descontinuidade de ocupação. Apresentam população urbana e densidade demográfica elevadas, forte articulação econômica, intensos fluxos de relações intermunicipais com comutação diária, complementaridade funcional e população ocupada em atividades urbanas (setores secundário e terciário)" (IPARDES, 2000, p.68. Grifo nosso). Segundo Firkowski (2001), o aglomerado me- 
ropolitano de Curitiba quanto ao processo de revisão obrigatória de seus respectivos planos diretores.

\begin{tabular}{|c|c|c|}
\hline $\begin{array}{l}\text { SITUAÇÃO DO PD } \\
\text { (fev./2016) }\end{array}$ & MUNICÍPIO & LEI PLANO DIRETOR \\
\hline \multirow{6}{*}{$\begin{array}{c}\text { VIGENTE } \\
\text { (extrapola o prazo de revisão) }\end{array}$} & Almirante Tamandaré & Lei Complementar $n^{\circ} 01 / 06$ \\
\hline & Araucária & Lei Complementar $n^{\circ} 05 / 06$ \\
\hline & Fazenda Rio Grande & Lei Complementar $\mathrm{n}^{\circ} 04 / 06$ \\
\hline & Quatro Barras & Lei $n^{\circ} 01 / 06$ \\
\hline & Campo Magro & Lei $n^{\circ} 717 / 12^{*}$ \\
\hline & Pinhais & Lei $n^{\circ} 1232 / 11^{* \star}$ \\
\hline \multirow{3}{*}{ EM REVISÃO } & Campo Largo & Lei $n^{\circ} 1812 / 05$ \\
\hline & Colombo & Lei $\mathrm{n}^{\circ} 875 / 04$ \\
\hline & Piraquara & Lei $n^{\circ} 854 / 06$ \\
\hline \multirow{3}{*}{$\begin{array}{c}\text { REVISADO } \\
\text { (2² geração pós-EC) }\end{array}$} & Curitiba & Lei $n^{\circ} 14771 / 15$ \\
\hline & São José dos Pinhais & Lei Complementar $n^{\circ} 100 / 15$ \\
\hline & Campina Grande do Sul & Lei Complementar $n^{\circ} 18 / 15$ \\
\hline
\end{tabular}

Quadro 2 - SITUAÇÃO DOS PLANOS DIRETORES DO RECORTE ESPACIAL EM RELAÇÃO À REVISÃO OBRIGATÓRIA - 2016. FONTE: Site Leis Municipais (www.leismunicipais. com.br), organizado pela autora (2016).

Nota: *O município de Campo Magro elaborou sem primeiro PD em 2012.

**A Lei n505/01 foi revogada pela lei de 2011, sem a realização de processo de revisão do plano diretor.

tropolitano de Curitiba corresponde à dinâmica metropolitana e compreende a mancha de ocupação contígua, ou seja, municípios vizinhos e com alta densidade e mancha de ocupação única, sendo, portanto, composta por Curitiba e mais 11 municípios de um total de 29 que compõem a Região Metropolitana de Curitiba (RMC), quais sejam: Almirante Tamandaré, Araucária, Campina Grande do Sul, Campo Largo, Campo Magro, Colombo, Fazenda Rio Grande, Pinhais, Piraquara, Quatro Barras e São José dos Pinhais. 
A partir da análise dos planos diretores dos municípios que compõem o recorte espacial, é possível identificar quatro níveis distintos quanto ao estágio de incorporação do EIV, quais sejam:

- $\quad$ Nível A - inexistente: o instrumento EIV não está incluído na lei do PD (Campo Largo);

- Nível B - existente, porém de forma nominal: o EIV é mencionado no rol de instrumentos de política pública do município e/ou sua aplicação é associada a outro instrumento (Campo Magro e Pinhais);

- Nível C - existente, em capítulo específico: a função e as características do instrumento são descritas em artigos da lei do PD, que reforçam a necessidade de lei municipal posterior para regulamentar sua aplicação (Almirante Tamandaré);

- $\quad$ Nível D - existente, em capítulo específico, com detalhamento: além de conter a função e as características do instrumento, a lei do PD inclui mais detalhes sobre sua aplicação, tais como: medidas mitigadoras ou compensatórias; inclusão de novos critérios de análise do impacto urbano além daqueles previstos no artigo 37 do Estatuto da Cidade; o conjunto de secretarias municipais que participa do processo de análise do estudo também é incluído; e, em alguns casos, são elencadas as tipologias de empreendimento e/ou atividades sujeitas à sua aplicação. Essa é a 
situação recorrente no aglomerado metropolitano de $\mathrm{Cu}$ ritiba, o que corresponde a $58 \%$ dos municípios (Quatro Barras, Fazenda Rio Grande, Curitiba, Araucária, Campina Grande do Sul, Colombo, Piraquara, São José dos Pinhais). Cabe destacar que, atualmente ${ }^{8}$, parte dos municípios do aglomerado está em processo de revisão do PD (Campo Largo, Colombo e Piraquara) e alguns, ainda que vigentes, estão completando o ciclo de 10 anos, aproximando-se do período de início desse processo (Almirante Tamandaré, Araucária, Fazenda Rio Grande e Quatro Barras). Sendo assim, os níveis/estágios de incorporação do EIV pelos planos diretores municipais tendem a sofrer modificação nos próximos anos.

Ao se analisar a aplicabilidade do EIV no aglomerado metropolitano de Curitiba, o conjunto de municípios que apenas incorporou o instrumento no PD corresponde a 50\%, considerando-se todos os níveis de incorporação identificados ( $B, C$ e $D)$, indo da mera menção ao instrumento (Campo Magro e Pinhais) à inclusão das tipologias de empreendimentos sujeitas à elaboração do estudo (Fazenda Rio Grande e Quatro Barras). Dentre os municípios que incorporaram, o que corresponde em números absolutos a 11 municípios, apenas 5 apresentam regulamentação posterior, ou seja, $45 \%$.

8. Para a conclusão desta pesquisa, foi estabelecida uma data limite para a atualização desse processo: 01 de fevereiro de 2016. 
A ausência de regulamentação em Curitiba pode ser vista com certa surpresa, uma vez que o município tem sido considerado, por muitas décadas, referência em planejamento urbano. Maiores investigações com a relação à não regulamentação do instrumento e à insistência no uso do RAP, definido em 1997, precisam ser ainda realizadas; assim como em relação ao "Sistema EIV", proposto no novo PD aprovado em 2015, que depende de regulamentação posterior para iniciar o funcionamento.

\section{Especificidades da aplicação do Estudo de Im- pacto de Vizinhança nos municípios do aglom- erado}

Dos cinco municípios que possuem o instrumento regulamentado (FIGURA 1), apenas dois o aplicam de maneira contínua há pelo menos cinco anos, sendo eles Araucária e São José dos Pinhais. A seguir, são apresentados alguns achados de pesquisa sobre a aplicação do EIV nesse conjunto de municípios.

\section{Araucária}

Situado a sudoeste de Curitiba, o perímetro urbano de Araucária limita-se ao norte e leste com o polo, com os municípios de Campo Largo ao norte, Balsa Nova e Contenta a oeste, Fazenda Rio Grande, Mandirituba a leste, e Quitandinha ao sul (FIGURA 1). Possui uma população de 119.123, 


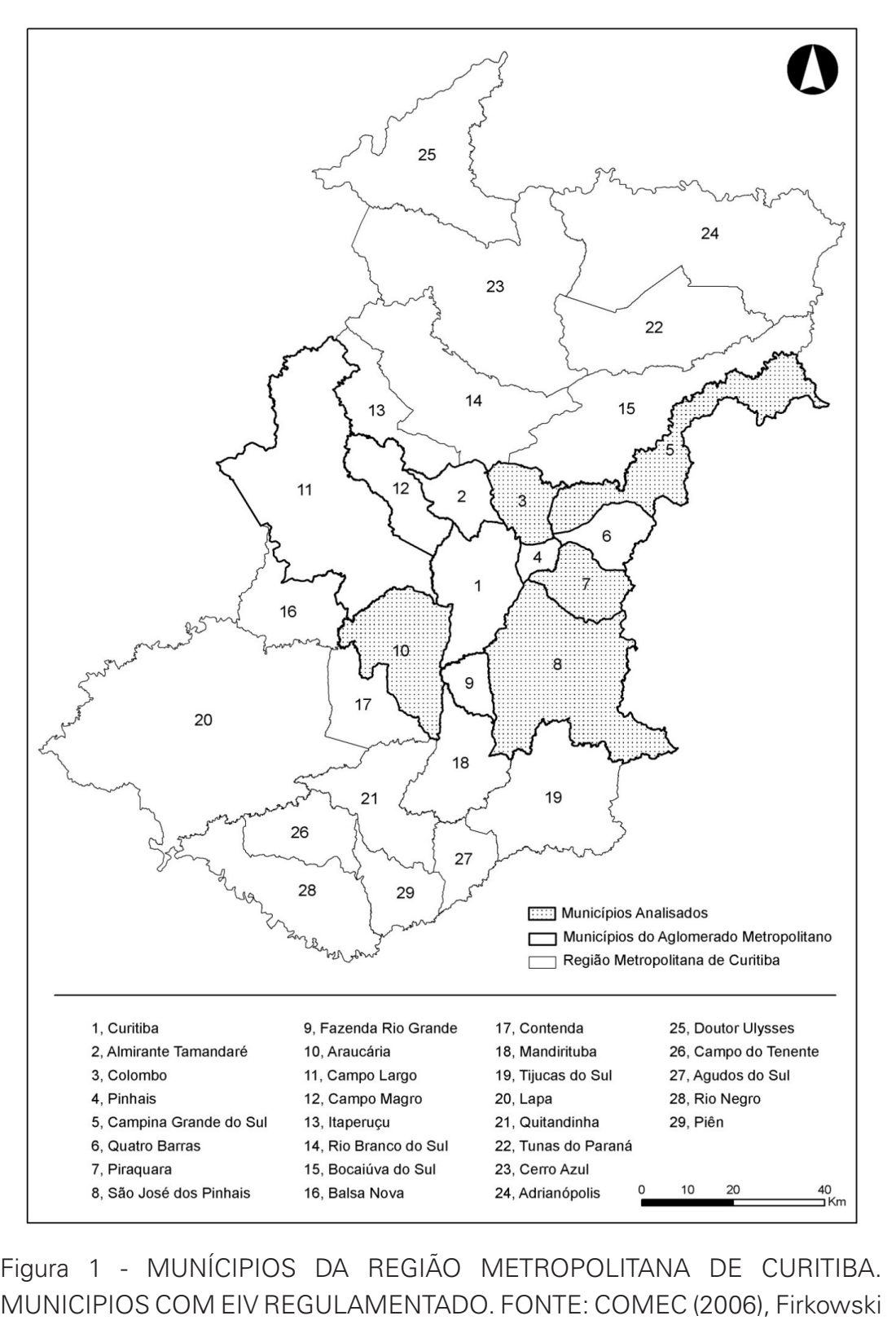


sendo que desse total 92,5\% corresponde à população urbana. Em relação ao aglomerado metropolitano, representa $4 \%$ da população. Segundo projeção apresentada pelo IBGE (2010), a população estimada do município para 2015 é de 133.428 habitantes, um crescimento de $12 \%$.

O PD do Município, definido pela Lei Complementar $n^{\circ} 05$ (ARAUCÁRIA, 2006), trata do instrumento em quatro momentos. Primeiramente, o inclui no rol de instrumentos jurídicos e urbanísticos da política municipal (art. 81, XI); em seguida, menciona a necessidade de sua elaboração para cada Operação Urbana Consorciada aprovada $(118$, V); inclui um capítulo específico (artigos 125 a 131); e, por fim, inclui o EIV na relação de instrumentos de democratização da gestão municipal, que são entendidos como "aqueles que têm por objetivo promover a gestão municipal descentralizada e participativa" (art.142).

Araucária aplica o instrumento desde 2009 com base no capítulo específico contido no Plano Diretor. Apenas em 2011 as orientações para a elaboração e apresentação do EIV foram estabelecidas, com a aprovação da Resolução $n^{\circ}$ 03 (ARAUCÁRIA, 2011) pelo Conselho Municipal do Plano Diretor (CMPD).

Os anexos que compõem essa resolução visam auxiliar as equipes na elaboração do EIV, o qual deverá abordar: (i) caracterização do terreno/lote e do entorno e memorial descritivo do empreendimento; (ii) impactos no período da obra; 
(iii) impactos no período de operação; e (iv) proposições para mitigar e/ou compensar os impactos negativos e potencializar os impactos positivos. Ainda, quanto à realização de audiência pública, são expostas orientações para sua realização e também sobre como o estudo deve ser apresentado nesse momento do processo de avaliação.

A Resolução nº 02 (ARAUCÁRIA, 2012) estabelece o fluxo de ações e procedimentos de apresentação, avaliação e aprovação do EIV. As responsabilidades de cada um dos agentes que participam do processo de aprovação também estão definidas na Resolução nº2/12. Cabe destacar que os ônus definidos pelo Município, decorrentes dos impactos urbanos gerados, ou seja, a execução das medidas mitigadoras e/ou compensatórias, são de total responsabilidade do empreendedor (proprietários dos meios de produção, proprietário fundiário e promotor imobiliário), enquanto que à Prefeitura (Estado) compete analisar o estudo e divulgá-lo à população interessada por meio da realização de audiências públicas.

Araucária tem tido uma experiência positiva na intenção de promover a gestão democrática, realizando audiências públicas como parte do processo de aprovação dos EIVs. A divulgação da audiência ocorre por meio do site da Prefeitura e também pelo Diário Oficial, constando data e os estudos que serão apresentados; em uma mesma audiência geralmente são apresentados vários EIVs ${ }^{9}$. No entanto, 
conforme destacado pelos técnicos da Secretaria Municipal de Planejamento ${ }^{10}$, órgão responsável pela tramitação do EIV na Prefeitura, a participação da população tem sido tímida. O maior público participante de uma audiência foi registrado após a realização de uma estratégia de divulgação diferente, em que panfletos contendo informações como data e horário da audiência, assim como quais os projetos que seriam apresentados, foram distribuídos na vizinhança dos empreendimentos.

Dentro das tipologias de empreendimento e atividades em que a aplicação do instrumento é obrigatória, estabelecidas tanto pelo Plano Diretor como pela Resolução n 03/11, foram analisados mais de 70 EIVs, desde que o Município passou a aplicar o instrumento.

As tipologias de empreendimentos e atividades que foram submetidas à análise nesse período (2009-2015) são apresentadas no GRÁFICO 3. Pode-se observar que praticamente metade dos projetos submetidos para análise são de indústrias, enquanto que o uso habitacional corresponde a aproximadamente $30 \%$. As demais tipologias (edifícios religiosos, de serviço, supermercados e diversos), somadas, contabilizam os $20 \%$ restantes.

9. O Município já realizou 25 audiências públicas. A última ocorreu em outubro de 2015.

10. Foram realizadas entrevistas nos seguintes municípios: Araucária, Campina Grande do Sul, Colombo, Piraquara e São José dos Pinhais em fevereiro de 2016. 


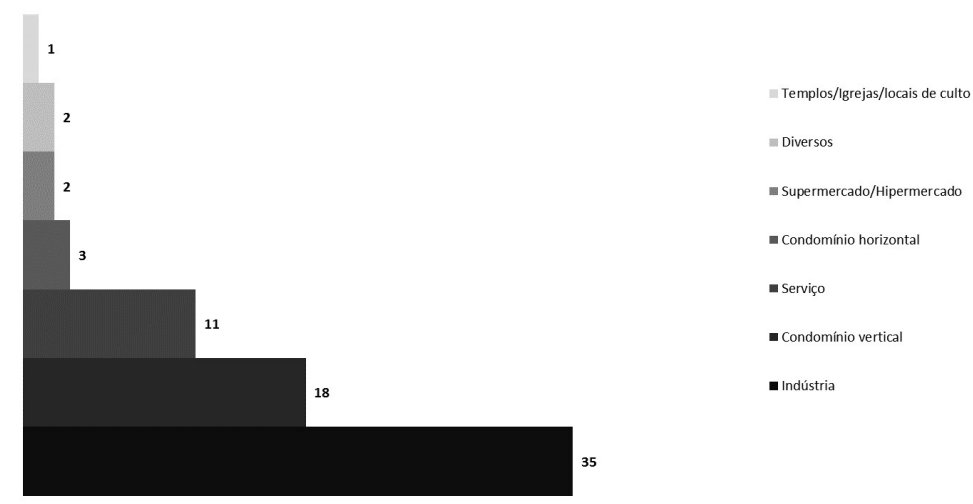

Gráfico 3 - NÚMERO DE EIVs ANALISADOS PELA PREFEITURA MUNICIPAL DE ARAUCÁRIA, POR TIPOLOGIA, 2009-2015. FONTE: Secretaria de Planejamento (2016), organizado pela autora (2016).

A equipe responsável pela análise dos EIVs é composta por técnicos das Secretarias Municipais de Urbanismo, Planejamento e Meio Ambiente. No entanto, é o Conselho Municipal do Plano Diretor (CMPD) o responsável por aprovar ou não os estudos submetidos. Esse conselho é formado por técnicos das seguintes Secretarias: Educação, Meio Ambiente, Urbanismo, Planejamento, Finanças, Saúde e a Companhia de Desenvolvimento do Município de Araucária (CODAR) e, também, membros da sociedade civil (conselhos de classe, organização não governamental, associação de moradores).

Alguns entraves identificados pela equipe da Secretaria de Planejamento no processo de aplicação do EIV estão relacionados: (i) à definição das áreas de influência, que fica a cargo do empreendedor, ou seja, da equipe técnica 
contratada para a elaboração do estudo e, com isso, existe uma enorme variedade de áreas que não estão relacionadas necessariamente com os impactos analisados; (ii) ao uso de aspectos/critérios definidos para a elaboração de EIA/RIMA na elaboração de muitos EIVs submetidos; e (iii) à formação das equipes técnicas que elaboram os EIVs, que, em muitos casos, são compostas por engenheiros ou técnicos ambientais e, portanto, não apresentam a diversidade de profissionais que um estudo multidisciplinar exige.

Isso significa que é frequente a submissão de EIVs que negligenciam os demais aspectos. Com isso, o processo de tramitação é interrompido diversas vezes e o Estudo é devolvido para que o empreendedor complemente a análise desses impactos. Portanto, ainda que as propostas de contrapartidas sejam apresentadas pelo empreendedor, elas podem ser alteradas ao longo do processo por três diferentes instâncias de análise: a equipe técnica que analisa o EIV; o CMPD e as decisões resultantes da audiência pública. Logo, as alterações e complementações durante a tramitação do EIV, entre Município e empreendedor, decorrentes de aspectos negligenciados nas análises, podem também desencadear a não finalização do processo, conforme comentado anteriormente.

Uma solução proposta pela equipe técnica de Araucária e que vem sendo aplicada desde 2012 para tentar padronizar as entregas dos estudos, foi a definição de um modelo su- 
cinto que contêm as informações necessárias para a elaboração do EIV'1.

Com o objetivo de minimizar os entraves identificados ao longo dos sete anos em que o instrumento vem sendo aplicado no Município, está em processo de elaboração uma lei municipal específica.

\section{Campina Grande do Sul}

O Município está localizado a nordeste do aglomerado metropolitano, limitando-se, ainda, com Bocaiúva do Sul ao norte, Colombo a oeste e Quatro Barras a sul. (FIGURA 1) O censo demográfico de 2000 (IBGE) registrava uma população residente em área urbana de 25.961 habitantes. Em dez anos esse número passou para 31.961 habitantes, um crescimento populacional de mais de $23 \%$ apenas na área urbana. Em relação ao aglomerado metropolitano, a população do município representa 1,31\%. A população total estimada para 2015 é de 41.821 habitantes, registrando um crescimento de $7,87 \%$ em cinco anos.

A Lei $n^{\circ} 376$ (CAMPINA GRANDE DO SUL, 2015), que dispõe sobre o Estudo de Impacto de Vizinhança e respectivo Relatório de Impacto de Vizinhança - EIV/RIV foi regula-

11. O modelo do município de Araucária pode ser encontrado em: WÜTRICH, F. A aplicabilidade do Estudo de Impacto de Vizinhança no Aglomerado Metropolitano de Curitiba. 214f. Dissertação. (Mestrado em Geografia). Universidade Federal do Paraná, 2016. 
mentada em 2015 e é composta por dez artigos, além de um anexo que apresenta oTermo de Referência com o conteúdo mínimo que deve ser apresentado no estudo.

O Termo de Referência, anexo à Lei, detalha o conteúdo que deve ser apresentado no EIV/RIV, dividido em oito tópicos: (i) identificação do empreendimento e do responsável técnico; (ii) caracterização geral do empreendimento; (iii) caracterização do sistema construtivo do empreendimento; (iv) estabelecimento das áreas de influência do empreendimento; (v) diagnóstico da situação atual nas áreas de influência definidas; (vi) identificação e análise dos impactos ambientais na vizinhança, decorrentes das fases de construção e operação do empreendimento; (vii) proposição de medidas mitigadoras e/ou compensatórias, tanto para a fase de construção como para de operação; (viii) elaboração de programa de monitoramento dos impactos ambientais e da implantação de medidas a eles relacionadas, sejam para mitigar e/ou compensar.

Com relação ao item iv sobre a área de influência do empreendimento, o Município define como "as áreas geográficas a serem afetadas pelo impacto" e que podem ser diferentes, dependendo do aspecto a ser analisado, podendo ser: tráfego de veículos, circulação de pedestres, valorização/desvalorização imobiliária, uso do solo, etc., ou seja, relaciona a definição da área de influência com conjunto de aspectos mínimos previstos no artigo $4^{\circ}$ da mesma Lei 
(CAMPINA GRANDE DO SUL, 2015, p.6).

Conforme informação do Setor de Urbanismo, ainda não foi concluído nenhum processo de tramitação do EIV no Município, o que impossibilita a análise sobre a sua aplicabilidade. O conselho responsável pela sua análise e aprovação, no entanto, já foi estabelecido por meio da Lei n³88/15, que dispõe sobre a criação do Conselho Municipal de Gestão Territorial e Meio Ambiente do município de Campina Grande do Sul. O único empreendimento de impacto urbano em trâmite no momento em que a municipalidade foi consultada ${ }^{12}$ se refere a um loteamento de $120.500 \mathrm{~m}^{2}$.

\section{Colombo}

Localizado a nordeste de Curitiba, Colombo limita-se também com os municípios de Almirante Tamandaré a oeste, Rio Branco do Sul ao norte, Bocaiúva do Sul a nordeste, Campina Grande do Sul a leste, Quatro Barras a sudeste e Pinhais a sul. (FIGURA 1). O Município é o terceiro mais populoso da RMC, depois de Curitiba e São José dos Pinhais, com 212.967 habitantes e, desse total, 95,4\% residem na área urbana. Em relação ao aglomerado metropolitano, o município representa $7,24 \%$ da população total (IBGE,

12. Novamente, cabe relembrar que os contatos com os municípios que regulamentaram o instrumento foram realizados durante o mês de fevereiro de 2016. 
2010). O Censo 2010 (IBGE) projeta para o ano de 2015 um crescimento de $9,13 \%$ da população, em cinco anos.

O Plano Diretor de Colombo, regulamentado pela Lei n875 (COLOMBO, 2004a), trata do instrumento em diversos momentos, e o denomina Estudo Prévio de Impacto de Vizinhança, uma vez que o estudo é elaborado justamente com o objetivo de identificar previamente a implantação de determinados empreendimentos e/ou atividades e os possíveis impactos urbanos deles decorrentes.

Em um primeiro momento, a Lei menciona a necessidade de audiência pública, debates e consultas públicas quando da aplicação de instrumentos em que haja transformação de uma área, caso do EIV, como uma das medidas para a implementação da Estratégia para Gestão Democrática Urbana e Ambiental (art.39, IV, V). Em outros dois momentos ao longo do PD, a necessidade de elaboração de EIV é relacionada à aplicação de dois instrumentos indutores do desenvolvimento urbano: consórcio imobiliário (art.93, §3º, II) e operação urbana consorciada (art.101, §1ํ, V). Por fim, entre as competências do Conselho Municipal de Gestão Territorial e Ambiental (CMGTA) foi incluído "opinar sobre a concessão de licença submetida a Estudo Prévio de Impacto de Vizinhança nos termos desta Lei e da Lei de Uso e Ocupação do Solo" (art. 150, XIII).

A Lei n 877 (COLOMBO, 2004b) é a responsável por regulamentar o EIV no Município. Por meio de capítulo especí- 
fico, que conta com 15 artigos, são definidos os critérios para sua aplicação.

Diferentemente das tipologias definidas pela legislação e os critérios quantitativos estabelecidos para o cabimento ou não da elaboração de EIV, na prática, o Município exige a elaboração do estudo apenas para empreendimentos residenciais acima de 30 unidades.

Ademais, não existe procedimento registrado para o trâmite do processo e o número de EIVs submetidos ainda não foi sistematizado. Também não houve, até o momento, realização de audiências públicas para inclusão da população.

Uma vez que o PD estava em processo de revisão durante o ano de 2016, a expectativa dos técnicos municipais é que com o término do processo de revisão seja aprovada uma lei específica para tratar do instrumento para que maiores instruções sobre procedimentos sejam definidas. A carência de equipe técnica na Secretaria Municipal de Desenvolvimento Urbano e Habitação, que conta com apenas dois engenheiros e um arquiteto, também pode ser um dos motivos para a aplicação parcial do instrumento e ausência de informações sobre o processo de tramitação.

\section{Piraquara}

O Município está localizado a leste de Curitiba; além do polo, faz divisa com Quatro Barras ao norte, Pinhais a oeste, São José dos Pinhais (FIGURA 1). Segundo o Censo 
2000, a população urbana do Município era de 33.801 habitantes. Dez anos depois, no Censo 2010, esse número passou para 45.738 habitantes, o que representa um aumento de $35,31 \%$. Dentre os cinco municípios analisados, Piraquara possui o menor percentual de população urbana em comparação à população total, com apenas $49 \%$ de seus habitantes residindo em áreas urbanas, segundo dados do Censo 201013. Em relação ao total da população do aglomerado metropolitano, Piraquara contribui com 3,17\%. Ainda, segundo estimativas do Censo 2010, a população do Município teria ultrapassado a marca dos 100.000 habitantes no ano de 2015.

O Plano Diretor do Município, definido pela Lei no 854 (PIRAQUARA, 2006), trata do EIV em quatro momentos.

Primeiramente, o inclui no rol de instrumentos jurídicos e urbanísticos da política municipal (art. 88, X); em seguida, menciona a necessidade de sua elaboração em cada Operação Urbana Consorciada aprovada $(103$, V); inclui um capítulo específico (artigos 117 a 120); e, por fim, inclui o EIV na relação de instrumentos integrantes do processo de planejamento urbano, devendo ser regulamentado por meio de lei municipal específica (art.151, XII). A lei específica nº 891

13. Cabe esclarecer que o censo demográfico desconsidera a população do Guarituba como urbana, uma vez que ela está excluída do perímetro urbano do Município. Embora a origem do espaço derive do processo de urbanização/metropolização, ou seja, essa área é de fato urbana, ainda que a lei desconsidere. 
(PIRAQUARA, 2007), que dispõe sobre o instrumento, possui 19 artigos, que definem as características para sua aplicação no Município.

Ainda que o instrumento seja regulamentado no Município, desde 2008 apenas dois EIVs foram submetidos para análise desde então, segundo informações de um dos técnicos da Secretaria Municipal de Meio Ambiente e Urbanismo. Isso se deve principalmente às condições ambientais do Município, uma vez que 93\% do território corresponde à Área de Manancial de Captação de água. Enquanto os outros 7\% são compostos por Bacia Litorânea, Unidades de Conservação do Parque Estadual do Marumbi e o Parque Estadual da Serra da Baitaca sendo, portanto, áreas de proteção ambiental. Outra questão ambiental que dificulta a aprovação de qualquer empreendimento, seja gerador de grande impacto ou não, é a existência de aproximadamente mil nascentes no Município.

Diante da fragilidade ambiental, todos os projetos (de edificações, loteamentos e desmembramentos) tramitados no Município são enviados para o órgão ambiental estadual, o Instituto Ambiental do Paraná (IAP), por conta das questões ambientais e para o órgão de gestão metropolitana, a Coordenação da Região Metropolitana de Curitiba (COMEC), conforme estabelecido no artigo 13 da Lei n 6.766/79. 


\section{São José do Pinhais}

O Município está localizado a sudeste de Curitiba e delimita-se também com os municípios de Fazenda Rio Grande e Mandirituba a leste, Tijucas do Sul ao sul, Piraquara e Pinhais ao norte (FIGURA 1). Segundo dados do Censo 2010, São José dos Pinhais é o município mais populoso da RMC depois de Curitiba, com 264.210 habitantes, sendo que desse total $90 \%$ corresponde à população urbana. Em relação à população do aglomerado metropolitano, representa 8,98\%. Ainda, segundo projeção do IBGE (2010), a população estimada para 2015 corresponde a 297.895, com um crescimento de $12,7 \%$.

O primeiro Plano Diretor pós-Estatuto aprovado no Município, definido pela Lei Complementar n`9 (SÃO JOSÉ DOS PINHAIS, 2004), não trata de modo específico sobre o EIV e também não o inclui no rol de instrumentos de política urbana, apenas relaciona sua elaboração à construção de habitação de interesse social (art.15); à realização de operação urbana consorciada (art.30, V); e atribui ao Conselho Municipal de Planejamento e Desenvolvimento Urbano (CMPDU) analisar e emitir pareceres sobre os relatórios de EIV (art.43, IX).

No entanto, assim como ocorre no município de Colombo, é com base na Lei de Zoneamento, Uso e a Ocupação do Solo e Sistema Viário (SÃO JOSÉ DOS PINHAIS, 2005), 
que São José dos Pinhais aplica o instrumento. Embora não apresente um capítulo específico para tratar normas e procedimentos quanto à elaboração, tramitação, análise, mitigação e divulgação, o único artigo que trata do assunto é bastante extenso, totalizando sete parágrafos, que foram sendo complementados e corrigidos por leis posteriores ${ }^{14}$.

Com base nos casos de pertinência quanto à aplicação do instrumento, estabelecidos no caput do artigo 14 da Lei $n^{\circ}$ 16/05, foram analisados mais de 300 EIVs desde que o Município passou a aplicar o instrumento em meados de 2010.

Dentre as tipologias de empreendimentos e atividades analisadas nesse período, pode-se observar no GRÁFICO 4 que as indústrias correspondem a $25 \%$; os edifícios comerciais, depósitos de logística e barracões a 32\%; enquanto que EIVs de conjuntos habitacionais, sejam verticais ou horizontais, correspondem a $40 \%$ dos EIVs submetidos. Essas proporções confirmam a permanência da vocação industrial do Município (FIRKOWSKI, 2001), assim como a demanda por moradia, uma vez que foi registrado crescimento populacional de $29 \%$ em uma década.

Em relação aos critérios para análise dos estudos, previstos na lei n $16 / 05$, dependendo do projeto (atividade) e da área onde se pretende implantar o empreendimento (lo-

14. Lei Complementar n 29 (SÃO JOSÉ DOS PINHAIS, 2007) e Lei Complementar nº 58 (SÃO JOSÉ DOS PINHAIS, 2011). 
calização), são acrescidos novos critérios, especialmente relativos ao meio ambiente. Essa situação está relacionada ao fato de o Município possuir grande quantidade de rios, incluindo dois mananciais de abastecimento público (Rio Pequeno e Rio Itaqui).

Os entraves identificados no processo de aplicação do instrumento estão relacionados ao cumprimento das contra-

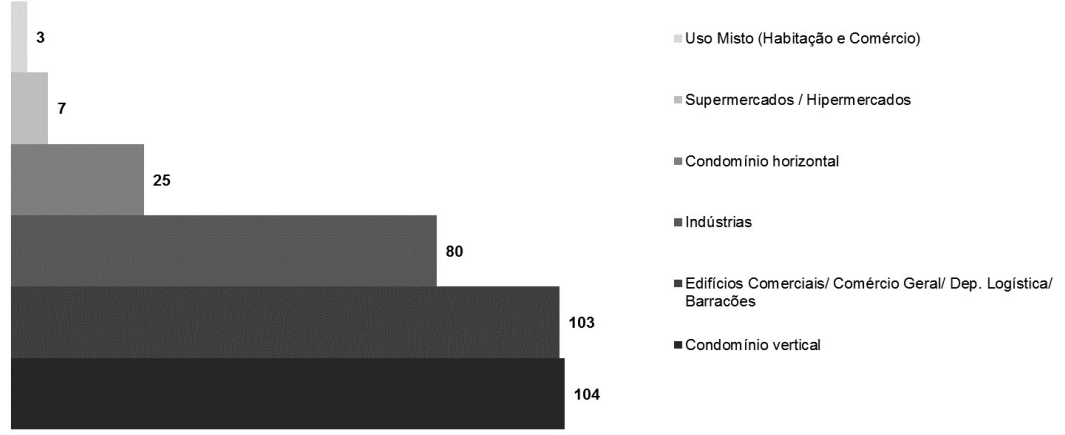

Gráfico 4 - NÚMERO DE EIVS ANALISADOS PELA PREFEITURA MUNICIPAL DE SÃO JOSÉ DOS PINHAIS, PORTIPOLOGIA, 2010-2016. FONTE: Secretaria de Urbanismo (2016), organizado pela autora (2016).

partidas, que, em muitos casos, ainda não estão finalizadas no momento em que a implantação do empreendimento já está concluída, aguardando a emissão do Certificado de Vistoria de Conclusão de Obra (CVCO) ${ }^{15}$. A demora no cumprimento das medidas exigidas para mitigar e/ou com-

15. Corresponde a um documento que certifica que a edificação anteriormente licenciada, por meio do Alvará de Construção, Reforma e/ou Ampliação, Reforma Simplificada ou Alteração encontra-se concluída. 
pensar os impactos urbanos previstos protela a emissão dessa certificação e pode gerar situações descritas pelos técnicos como "guerra de titãs", visto que gera um embate entre os grandes agentes produtores do espaço (CAPEL, 1974; GOTTDIENER, 1997): Estado, de um lado, e promotores imobiliários ou mesmo proprietários dos meios de produção, de outro.

O monitoramento e a fiscalização da execução das contrapartidas ficam a cargo do agente administrativo da secretaria municipal relacionada à medida mitigadora ou compensatória, definida dentre aquelas que fazem parte da equipe técnica de avaliação do estudo: Urbanismo, Obras, Trânsito e Transporte e Meio Ambiente. Tratando do objetivo da aplicação do instrumento, qual seja, a promoção da gestão democrática, não existem diretrizes legais para a realização de audiência pública em São José dos Pinhais, assim como os resultados obtidos no estudo e as contrapartidas definidas não são informadas à população

Durante o primeiro semestre de 2016, o Município estava desenvolvendo a revisão da Lei $n^{\circ} 16 / 05$, que dispõe sobre o Zoneamento, Uso e a Ocupação do Solo e Sistema Viário. A lei deverá trazer conteúdo referente à aplicação do EIV, incluindo o rol de tipologias de empreendimentos e atividades a ele sujeitos, conforme definido pela lei anterior. Deverão ser acrescentados novos casos de obrigatoriedade, trazidos pela experiência adquirida durante os anos 
em que o EIV vem sendo solicitado aos empreendedores. A elaboração da lei municipal específica para regulamentar a sua aplicação, conforme previsto no artigo 80 da segunda geração do Plano Diretor, portanto, foi postergada até que o processo de aprovação da lei de zoneamento seja finalizado.

Cabe ressaltar que não existe um acompanhamento do órgão de gestão metropolitano na implantação e aplicação do instrumento. No entanto, qualquer empreendimento situado na coroa de urbanização periférica, cuja área de influência extrapole o limite político-administrativo de um único município, por exemplo, representa um cenário em que diretrizes metropolitanas se fazem necessárias. O recémaprovado Estatuto da Metrópole (Lei Federal n 13.089/15), que estabelece uma nova escala de planejamento e gestão urbanos, que excede a municipal, pode representar um avanço nessa questão.

\section{Considerações finais}

A partir da análise da função do instrumento, as diretrizes propostas para sua aplicação e a análise de sua aplicabilidade no conjunto de municípios pesquisados, foram identificados alguns desafios e recomendações, tanto para técnicos municipais como para os profissionais responsáveis pela elaboração dos estudos, relativos a conteúdos complementares a serem incluídos nas leis específicas munici- 
pais.

A intenção do Estatuto da Cidade ao obrigar a elaboração de lei específica para regular a aplicação do instrumento objetiva, principalmente, a definição da relação de empreendimentos e/ou atividades sujeitos à elaboração do estudo para subsidiar o seu processo de licenciamento e aprovação, conforme a demanda do mercado e a realidade local. No entanto, diante do observado na revisão conceitual do instrumento e na pesquisa empírica, cabe apresentar algumas sugestões de conteúdo, a serem incluídas nessa lei, de modo a evitar interpretações confusas em relação ao propósito do instrumento:

- Conceitos relacionados ao EIV: alguns conceitos devem ser esclarecidos na legislação municipal de modo a garantir que o entendimento do município sobre a questão esteja claro para o empreendedor, quais sejam: (i) empreendimento e/ou atividade gerador de impacto urbano; (ii) impacto urbano; (iii) vizinhança; (iv) diferenças entre medidas adaptativas, mitigadoras e compensatórias; (v) público e privado; e (vi) área de influência direta e indireta;

- Relação entre o conjunto de aspectos a serem analisados e a proposição de medidas adaptativas, mitigadoras e compensatórias possíveis de serem exigidas: um artigo deve abordar cada uma destas questões separadamente. Porém, um terceiro artigo poderia associar as duas questões, relacionado os tipos de impactos (socioeconômicos, ambien- 
tais, paisagísticos, culturais e urbanos) com as contrapartidas apropriadas, para evitar que elas fiquem restritas ao sistema viário;

- Tramitação do EIV na prefeitura: seja por meio de descrição das etapas de avaliação, com inclusão de prazos ou por meio de fluxograma, essa informação deve constar na lei, pois deixa claro para o empreendedor todas as etapas do processo de avaliação e o tempo estimado;

- Definição de equipe técnica responsável pela elaboração do Estudo: diante da natureza multidisciplinar do EIV, que deve compreender os impactos socioeconômicos, culturais, paisagísticos, urbanos e ambientais e da recorrência de estudos que contemplam apenas aspectos relativos ao sistema viário ou que se valem de critérios do EIA para sua elaboração, faz-se necessário incluir na lei um artigo que exija equipe multidisciplinar, e indique as áreas de formação profissional desses integrantes;

- Responsabilidades do Município e do Empreendedor: a exemplo dos municípios de Araucária e Campina Grande do Sul, a especificação de atribuições e obrigações de cada um dos agentes sociais envolvidos deve ser explicitada, de modo a evitar mal-entendidos ou omissões de ambas as partes;

- Procedimentos para divulgação do EIV e realização de audiência pública: sugere-se a inclusão de um artigo que 
defina regras claras sobre a divulgação do estudo, que poderá ser por meio de nota no diário oficial do município, com os principais pontos apresentados no estudo, incluindo as contrapartidas definidas; assim como a data prevista para a realização de audiência pública;

- Inclusão do modelo de EIV anexo à lei: o município de Araucária elaborou um modelo, encontrado no site da prefeitura, que objetiva facilitar e uniformizar a entrega dos estudos, bem como garantir que todos os tópicos previstos no estudo sejam elaborados.

\section{Referências}

ARAUCÁRIA. Prefeitura Municipal. Lei Complementar $n^{\circ} 5$, de outubro de 2006. Institui o Plano Diretor, estabelece objetivos, instrumentos e ações estratégicas e dá outras providências para as ações de planejamento no município de Araucária. Paraná: Câmara Municipal de Araucária, 2006. Disponível em: <www.leismunicipais.com.br> Acesso em: 27 out. 2015.

ARAUCÁRIA. Prefeitura Municipal. Resolução n003, de 31 de março de 2011. Estabelece as orientações para elaboração e apresentação de Estudo de Impacto de Vizinhança (EIV). Conselho Municipal do Plano Diretor de Araucária, 2011. Disponível em: <www.araucaria.pr.gov.br> Acesso em: 27 out. 2015.

ARAUCÁRIA. Prefeitura Municipal. Resolução n02, de 03 de maio de 2012. Estabelece o fluxo de ações e procedimentos de apresentação, avaliação e aprovação de Estudo de Impacto de Vizinhança (EIV). Conselho Municipal do Plano Diretor de Araucária, 2012. Disponível em: <www.araucaria.pr.gov.br> Acesso em: 27 out. 2015.

BRASIL. Lei no 10.257, de 10 de julho de 2001 (Estatuto da Cidade). 
Regulamenta os Arts. 182 e 183 da Constituição Federal, estabelece as diretrizes gerais de política urbana e dá outras providências. Diário Oficial da União: Brasília, edição de 11 de julho de 2001. Disponível em: <http://www2.camara.leg.br/legin/fed/lei/2001/lei-10257-10-julho2001-327901-norma-pl.html> Acesso em: 26 maio 2015.

CÂMARA, DOS DEPUTADOS. Estatuto da Cidade: guia para implementação pelos municípios e cidadãos. Brasília, Instituto Polis, 2001.

CAPEL, Horacio. Agentes y estrategias en la producción del espacio urbano español. Revista de Geografía, vol. VII, nº 1-2, Universidad de Barcelona, 1974, p. 19-56. Disponível em <http://www.raco.cat/index. php/RevistaGeografia/article/view/45880/56672> Acesso em: 24 nov. 2015.

CAMPINA GRANDE DO SUL. Prefeitura Municipal. Lei n³76, de 22 de julho de 2015. Dispõe sobre o Estudo de Impacto de Vizinhança e respectivo Relatório de Impacto de Vizinhança EIV/RIV do município de Campina Grande do Sul, estado do Paraná. Paraná: Câmara Municipal de Campina Grande do Sul, 2015b. Disponível em: <www.leismunicipais.com.br> Acesso em: 27 nov. 2015.

COLOMBO. Prefeitura Municipal. Lei n̊875, de 16 de fevereiro de 2004. Institui o Plano Diretor do município de Colombo, estado do Paraná, e dá outras providências. Paraná: Câmara Municipal de Colombo, 2004a. Disponível em: <www.leismunicipais.com.br>. Acesso em: 09 nov. 2015.

COLOMBO. Prefeitura Municipal. Lei n877, de 16 de fevereiro de 2004. Institui as Normas de Uso e Ocupação do Solo no município de Colombo, estado do Paraná, e dá outras providências. Paraná: Câmara Municipal de Colombo, 2004b. Disponível em: <www.leismunicipais. com.br> Acesso em: 09 nov. 2015.

FIRKOWSKI, Olga L. de F. A nova territorialidade da indústria e o aglomerado metropolitano de Curitiba. 278f. Tese (Doutorado em Geografia Humana) - Faculdade de Filosofia, Línguas e Ciências Humanas, Universidade de São Paulo, São Paulo, 2001. 
GOTTDIENER, Mark. A produção social do espaço urbano. São Paulo: EDUSP, 1997.

IPARDES. Redes urbanas regionais: Sul. (Série Caracterização e tendências da rede urbana no Brasil, v. 6). Brasília: Convênio IBGE, UNICAMP/IE/NESUR, IPEA, 2000. Disponível em: <http://repositorio.ipea. gov.br/bitstream/11058/3080/1/Livro-Redes \%20urbanas\%20regionaisSudeste> Acesso em: 31 jan. 2016.

MUNICIPAIS, IBGE (2005). Pesquisa de Informações Básicas. Perfil dos municípios Brasileiros. Rio de Janeiro: Instituto Brasileiro de Geografia e Estatística. Disponível em: <http://www.ibge.gov.br/home/estatistica/economia/perfilmunic/> Acesso em: 28 nov. 2015.

MUNICIPAIS, IBGE (2013). Pesquisa de Informações Básicas. Perfil dos municípios Brasileiros. Rio de Janeiro: Instituto Brasileiro de Geografia e Estatística. Disponível em: <http://www.ibge.gov.br/home/estatistica/economia/perfilmunic/> Acesso em: 28 nov. 2015.

PIRAQUARA. Prefeitura Municipal. Lei n854, de 09 de outubro de 2006. Institui o Plano Diretor, estabelece objetivos, instrumentos e diretrizes para as ações de planejamento no município de Piraquara e dá outras providências. Paraná: Câmara Municipal de Piraquara, 2006. Disponível em: <www.leismunicipais.com.br> Acesso em: 09 nov. 2015.

PIRAQUARA. Prefeitura Municipal. Lei n891, de 18 de maio de 2007. Dispõe sobre o Estudo de Impacto de Vizinhança - EIV e o Relatório de Impacto de Vizinhança - RIV, e dá outras providências. Paraná: Câmara Municipal de Piraquara, 2007. Disponível em: <www.leismunicipais. com.br> Acesso em: 09 nov. 2015.

ROCCO, Rogério. Estudo de Impacto de Vizinhança: Instrumento de Garantia do Direito às Cidades Sustentáveis. Rio de Janeiro: Ed. Lumen Juris, 2009.

SÃO JOSÉ DOS PINHAIS. Prefeitura Municipal. Lei Complementar n9, de 23 de dezembro de 2004. Institui o Plano Diretor do município de São José dos Pinhais, estado do Paraná. Paraná: Câmara Municipal 
de São José dos Pinhais, 2004. Disponível em: <www.leismunicipais. com.br> Acesso em: 22 fev. 2016.

SÃO JOSÉ DOS PINHAIS. Prefeitura Municipal. Lei nº16, de 11 de novembro de 2005. Dispõe sobre o Zoneamento, o Uso e a Ocupação do Solo e Sistema Viário do Município de São José dos Pinhais, estado do Paraná. Paraná: Câmara Municipal de São José dos Pinhais, 2006. Disponível em: <www.leismunicipais.com.br> Acesso em: 09 nov. 2015. 